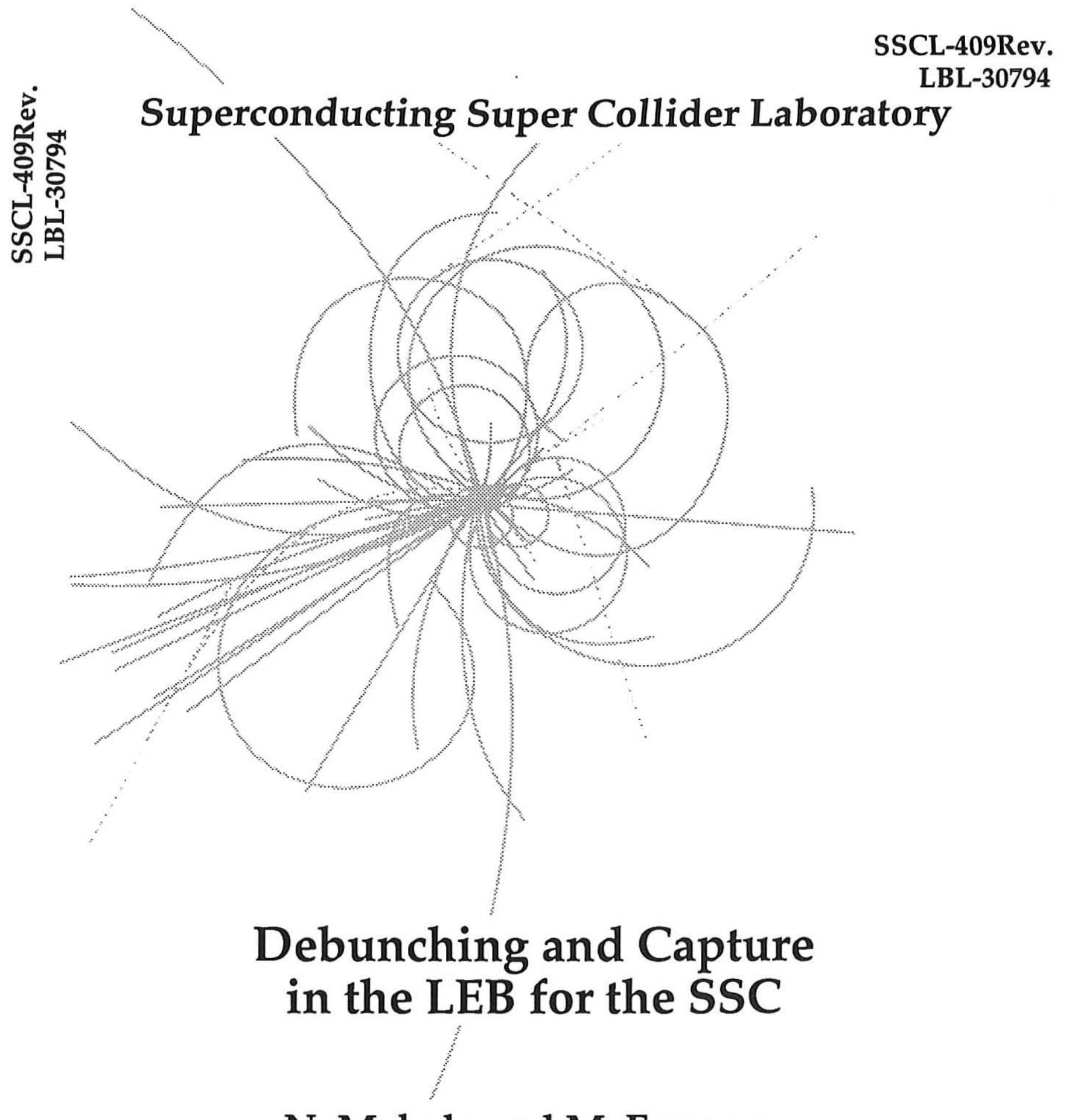

N. Mahale and M. Furman

May 1991 


\title{
Debunching and Capture in the LEB for the SSC*
}

\author{
N. K. Mahale \\ Superconducting Super Collider Laboratory ${ }^{\dagger}$ \\ 2550 Beckleymeade Avenue \\ Dallas, TX 75237 \\ and \\ Miguel A. Furman \\ Lawrence Berkeley Laboratory \\ University of California \\ Berkeley, CA 94720
}

May 1991

* Presented at the 1991 IEEE Particle Accelerator Conference, San Francisco, CA, May 6-9, 1991.

$\dagger$ Operated by the Universities Research Association, Inc., for the U.S. Department of Energy under Contract No. DE-AC02-89ER40486. 


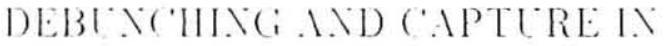 THI: I.EB FOR THE SSO
}

\author{
‥K. Mahale \\ Superconducting Supercollider Laboratory* \\ 2550 Becklermeade . Ire. Dallas. TX 75237 \\ and \\ Miguel \. Furman \\ Lawrence Berkley Laboratory \\ Iniversity of California \\ Berkeler: ( $\triangle 194720$
}

\begin{abstract}
We present the details of the capture process in the Low linergy Booster (LEB) for the SSC. We consider only the longitudinal dymanics. Space charge forces are computed quasistatically. The beam pipe is considered to be perfectly conducting. With respect to maximizing the capture - Hiciency and minimizing the space charge tune spread. iniral fow milliseconds are very important. We present only the first few milliseconds of the cycle, during which space dharge ellects are significant. For the numerical simulation we use the code FSIIt.
\end{abstract}

\section{Introduction}

The Low Energy Booster (LEB) is the first of the synchrotrons of the SSC accelerator complex. This makes the LEB a critical and complex machine. The LEB has to capture several hunches coming from the LINAC and bunch them into a single bunch. and accelerate them from $\beta=$ 1). 7924 to 0.9969 . This gives rise to several problems in the design of the I.E.B. The most important problem. of course. is the sinnificant space charge forces during the initial stage of the cycle. To understand the effect of space charge forces onc hat to consider the longitudinal and transverse dynamics: this is the subject of another study. preliminary results of which are presented at these proceedings[1]. Here we will. however. confine ourselves to the longitudinal dynamics and construction of the if voltage program for the I. LiB. W. do not wish to discuss the advantages and disadvantanes of different capture procedures. We present here the adiabatic capture process: we, lowever. remark that the IINAC frequency has been selected such that the painting scheme could also be adopted.

In acliabatic capture in a resonant system, it is customary ciller to inject in advance of the momentum curve or 11) inject a little abow the reference energy. This is done to achicve debunching of the linac bunches and to capture the while the synchronous phase is low. For example the 1.N. booster injects about 100 microseconds before the lwottom of the magnet ramp curve[2]. Similar results can

- ()perated loy lhe liniversities Research Association Inc. for 1h. I... Department of Energy: under contract No. DE-ACO2-

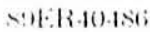

\begin{tabular}{|c|c|}
\hline Paraneter & Nominal Value \\
\hline Kinetic Energy & $600 \mathrm{MeV}$ \\
Longitudinal emittance(rms) & $6 \times 10^{-\top} \mathrm{eV} s$ \\
Energy Spread(rms) & $0.105 \mathrm{MeV}$ \\
Length(rms) & $1.63 \mathrm{~cm}$ \\
Jitter(rms) & $0.075 \mathrm{MeV}$ \\
Transverse Emittance(rms) & $0.4 \pi \mathrm{mm} \mathrm{mrad}$ \\
\hline
\end{tabular}

Table 1: Microbunch Characteristics

be obtained by injecting at the bottom of the momentum curve but at some what higher energy[3]. In the of program we propose here we do not do either. The resultant transmission and bunching factor, however, are similar to the FNAL booster. Ideas involved in the construction of the of voltage program are explained in Section 4.

\section{Injection Parameters}

Although the actual particles injected are $\mathrm{H}^{-}$ions, they are immediately stripped of the two electrons in the stripping foil. The injection into the LEB is multi-turn; here we consider four turn injection. In each turn the LINAC: will inject 9 microbunches into each of the LEB bucket. The of frequency of the IISAC will be so adjusted that the 36 microbunches in an LEB bucket will be equally spaced. The microbunches at the end of the LINAC: have a large energy spread: however. after passing through a drift and a compressor the energy spread is reduced[4]. During this process the microbunch is sheared (in phase space) so that it becomes longer, thereby reducing the charge density along the bunch. In addition to the energy spread the average energy of the microbunches has a jitter. Table 1 summarizes the characteristics of the microbunches.

\section{LEB Parameters}

The LEB has superperiodicity of three with three long straight sections. One of the straight sections is for the rf cavities and the other two are for injection and extraction. The parameters relevant to longitudinal dynamics are 


\begin{tabular}{|c|c|}
\hline 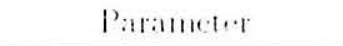 & Vinminal lainu. \\
\hline Injection .1/ontentum & $121: 1, c_{1}, 1$ \\
\hline Extraction momentm & $12 c_{1} \cdot 1 \%$ \\
\hline Ilarmonic Ximulor & lis \\
\hline (ircumfremente & illi 111 \\
\hline liansition (ianmuna & $\because 120$ \\
\hline Transverse Tinne & $11 x$ \\
\hline Repetition rate & $1011 \%$ \\
\hline Maximum of voltag" & 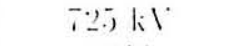 \\
\hline Protons/LEB-hunch & $1 i j^{10}$ \\
\hline
\end{tabular}

Table 2: The LEB Parameters

listed in Table 2 above. These parameters have changed recently: the new parameters are given in these proceedings $[5]$.

\section{The Rf Voltage Program}

As noted above. construction of the tf voltage program should minimize the space charge tune spread (a measure of which is given by Lasslet lune shift) and have an adequate transmission. ('omplete debunching will require ? small synchronous phase angle to capture a high fraction of particles. This, in turn, requires a high of voltage. Higher voltage, though, gives a large buclict area. does not guarantee that bunch area will be large. It is the bunch area and how tightly the bunch fills the bucket that determines a favorable bunching factor. For a given bunch area a smallheight bucket (but higher than the bunch) tends 10 give a longer and small-height bunch. The allowable bunch area. of course, is determined by the limits on the if voltage. This then determines the energy spread necessary for the microbunch. Thus the of voltage must be so constructed that the bucket is quite full. Once the relativistic effect more than compensates the hunching process. however. the bucket area should be further increasial to prevent the loss due to slow attrition during the acceteration cycle.

Cood transmission. in addition to avoiding long term attrition. must also capture a good fraction of particles in the intial moments. Wie achirw this hy a partial. ather than a complete, debunching of the microbunches. More details of this mechanism are given che where[6]. Here we present the resulting of progran.

Figure 1 shows the bucke area as a function of time. for the first $30 \mu$ s.s (about 13 turns) the voltage is kept at a minimum. preferably at zero; we have used the value of $4 \mathrm{kV}$ as practicable. Then the voltage is smoothly but rapidly increased up to (0.5) uns such that a bunch fills the bucket quite tightly. The bunch area (95\%) at this moment is about .03, el's in comparison to the bucket area of $0.038 \mathrm{el}$-s. The bucket area is maintained at $038 \mathrm{eV}$ s up $103 \mathrm{~ms}$, by which time the relativistic effect is able to compensate further bunching. This tight a bunch can not

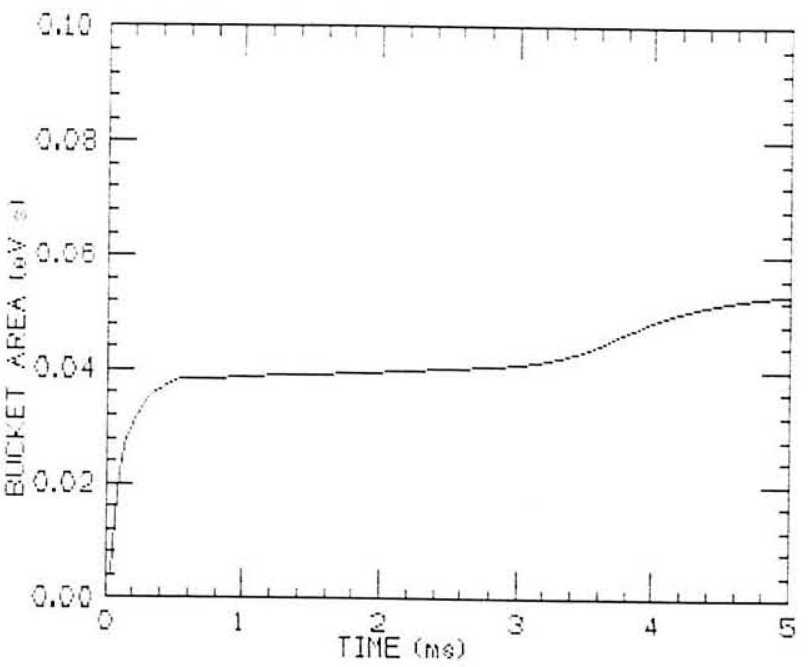

Figure 1: Bucket Area is Time

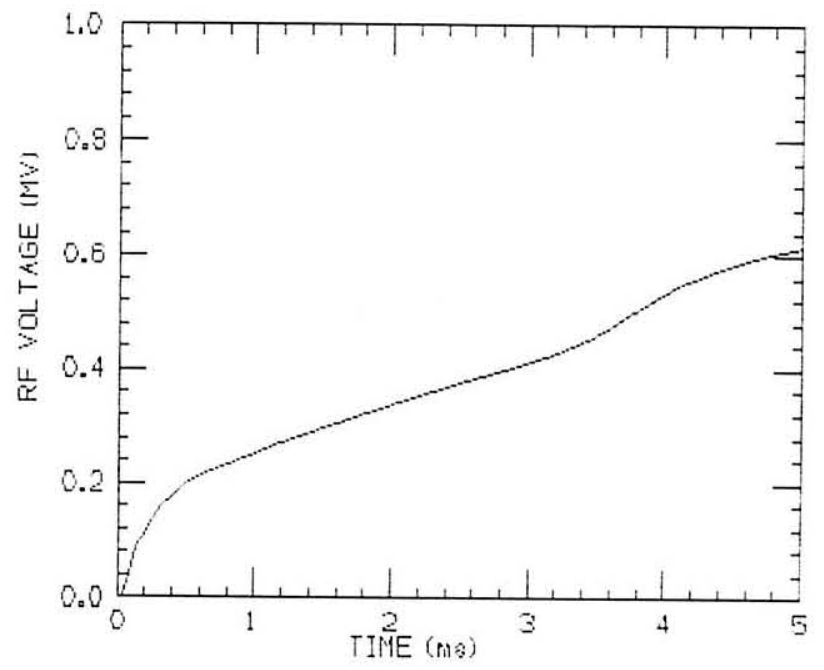

Figure 2: Rf Voltage vs Time

be maintained without further loss of particles as the synchronous phase angle is increased. Therefore the bucket area is further increased to $.054 \mathrm{eV}$ s between 3 to. $5 \mathrm{~ms}$ This buclet area is then maintained (not shown in the figure) until $30 \mathrm{~ms}$, beyond which it can not he maintained due to the decrease in the value of slip factor and phase angle. Based on the above ideas the rt voltage program, the first $5 \mathrm{~ms}$ of which is shown in Figure 2. was constructed using the program RAMPRF presented else where in these proceedings[i].

\section{$5 \quad$ Simulation and Results}

We use the code ESME for the tracking simulation. 43.200 particles (1200 in each microbunch) were tracked. To account for the jitter in the energy. the energy spread and the jitter were added in quadrature. Space charge effects including the conducting wall are included in the simulation. The space charge calculations are based on a qua- 


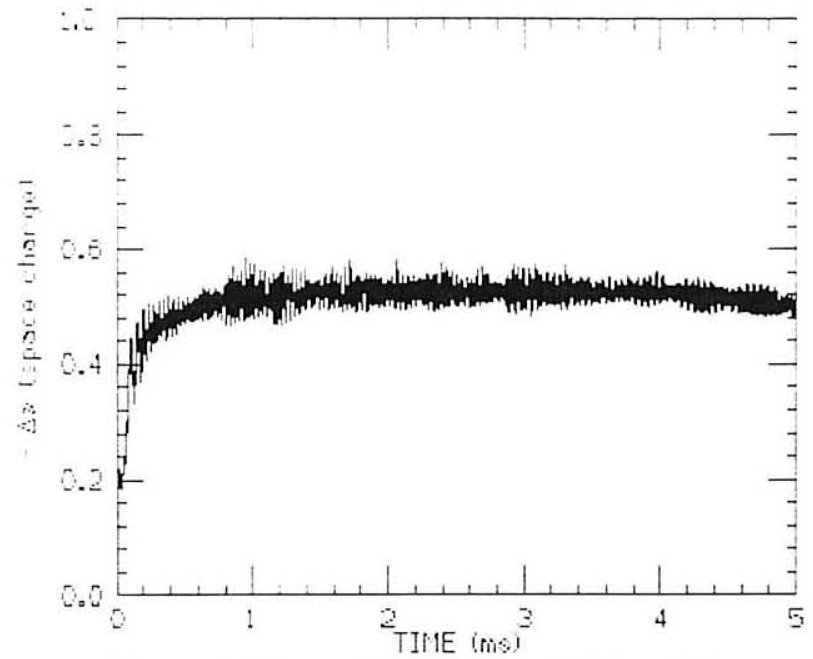

Figure 3: Space Charge une Shift vs Time

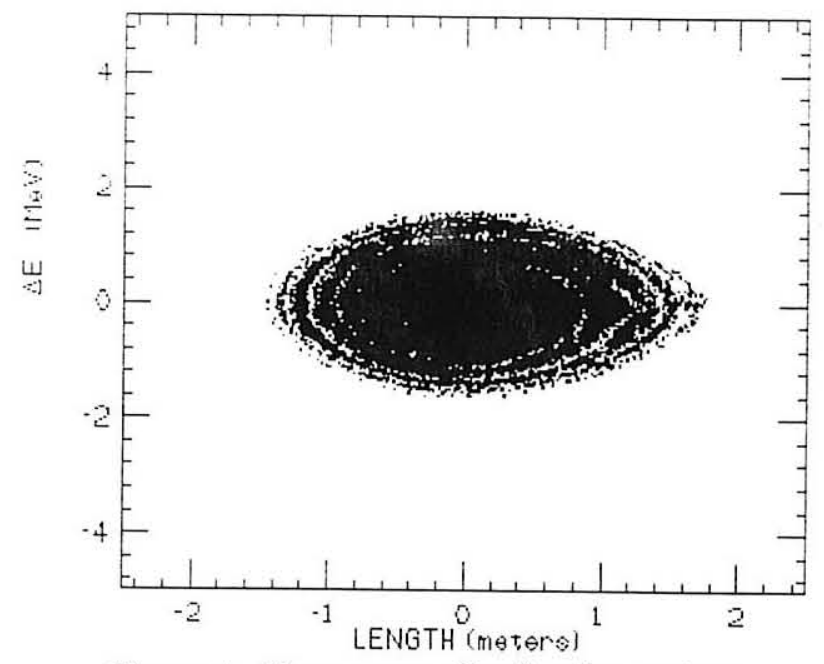

Figure 4: Phase space distribution at $1 \mathrm{~ms}$ sistatic evaluation as per the code ESME[E]. Due to the very small longitudinal emittance of the microbunches, for the first $1 \mathrm{~ms}$, it was necessary to give nine kicks per turn for a proper estimate of the space charge forces. Beyond 1 ms a single kick per turn gave adequate results; we, however, present the results using nine kicks per turn. The transverse beam size corresponds to the average value of the beta-function. The actual beam pipe is not circular, but rather an ellipse: the effective beam pipe radius used was the geometric mean of the two axes of the ellipse. A particle is assumed to be lost if its average closed orbit deviation is more than $2 \mathrm{~mm}$.

Figure 3 shows the space charge tune shift. The efficiency of capture. or transunission. is $98 \%$ for the entire $c y-$ cle. The longitudinal space charge lorces reduce the transverse tune shift by about $20 \%$. The space charge effect, as seen from Figure 4. results in mixing of the particles and spreading the particles over most of the bucket area. The bunch area(95\%) at 3 ms is athout $.030 \mathrm{eV}$ s. The bunching factor at about 100 turns is comparable to the FNAL simulation $[2.6]$.

\section{Discussion}

The of voltage program. presented here, gives results comparable to the of program at the $F N A L[2,6]$ as far as transmission and bunching factors are concerned. Whether this will allow us to predict the behavior of the LEB using the FNAL booster as an experimental proof of transverse dynamics is not yet clear. There are several differences hetween the machines: for example superperiodicity, transition gamnia and syuchrotron tune. Another question is whether a simple scaling of the intensity and transverse smittance is theoretically sound. Though we can not give a rigorous proof. we expect that the rf program we propose, as far as adiabatic capture is concerned. is well optimized for good bunching factor and transmission.

\section{Acknowledgement}

We express thanks to Steve Stahl for a quick course on the code ESME. Numerous discussions with our colleagues, particularly Alex Chao, Richard York and Shinji Machida, are deeply appreciated.

\section{References}

[1] S. Machida, et., al., "Space Clarge Effects in the SSC Low Energy Booster", these Proctedings.

[2] S. Stahl and C. Ankenbrandt, "Simulation of the Capture Process in the Fermilab Booster", Procecdings 1987 IEEE Parlicle Accoleralor Conference held at Washington. D.C. (16-19.1/arch 1987) p.1114.

[3] S. Stahl, pricate communicalion.

[4] R. K. Bhandari and S. Penner. "Beam Transfer Between the Coupled Cavity Linac and the Low Energy Synchrotron Booster for the SSC". Proccedings of the 1990) Linear Accelerutor (onference p.411. September 1990.

[5] R. York, ct.. al.. "The Superconducting Supercollider Low Energy Booster: A Status Report", these Proceedings.

[6] N. K. Mahale and Miguel A. Furman, "Injection and Capture in the LEB", SSCL-109. to be published in near future.

[i] Miguel A. Furman, "RAMPRF: A Program for Synchronous Acceleration ". these Proccedings.

[8] J. A. MacLachlan, "Longitudinal Phasespace Tracking with Space (harge and Wall Coupling Impedance", Fermilab FN-1.46 (February 1987). 


\section{Disclaimer Notice}

This report was prepared as an account of work sponsored by an agency of the United States Government. Neither the United States Government or any agency thereot, nor any of their employees, makes any warranty, express or implied, or assumes any legal liability or responsibility for the accuracy. completeness, or usefulness of any information, apparafus, product, or process disclosed, or represents that its use would not infringe privately owned rights. Relerence herein to any specific commercial product, process, or service by trade name, trademark, manufacturer, or otherwise, does not necessarily constitute or imply its endorsement, recommendation, or favoring by the United States Government or any agency thereol. The views and opinions of authors expressed herein do not necessarily state or reflect those of the United States Government or any agency thereot. 


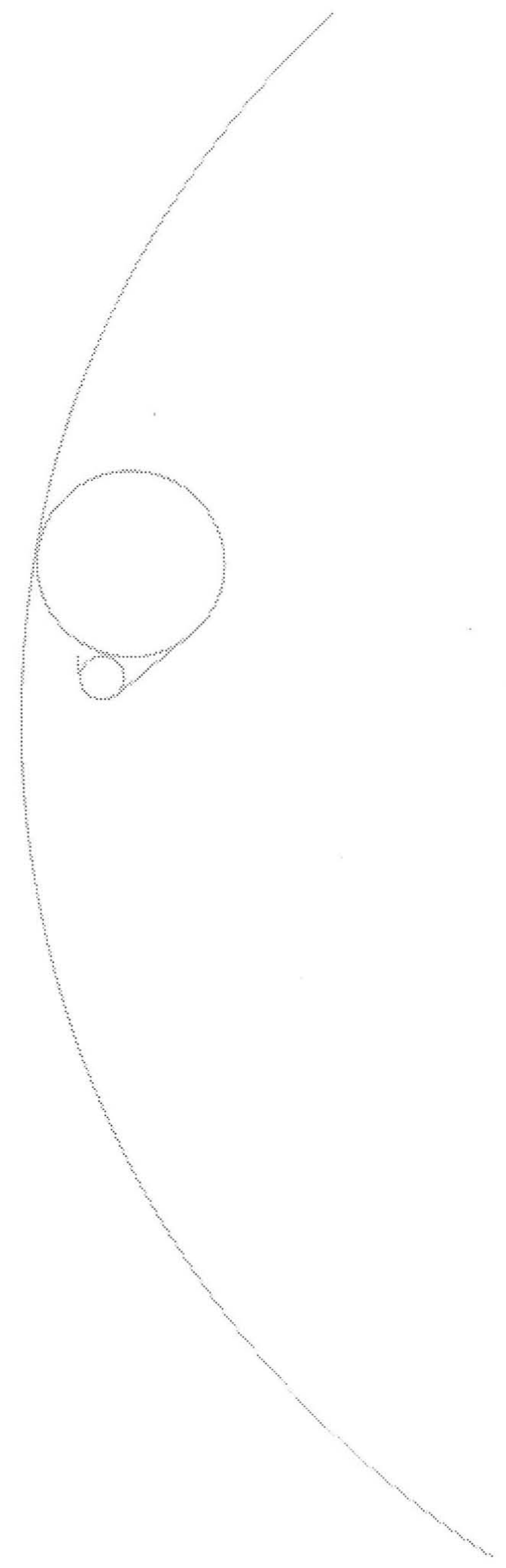

